\title{
The Effects of Integrated IT Support on the Prehospital Stroke Process: Results from a Realistic Experiment
}

\section{Magnus Andersson Hagiwara ${ }^{1}$ (D) - Lars Lundberg ${ }^{1}$ • Bengt Arne Sjöqvist ${ }^{2}$. Hanna Maurin Söderholm ${ }^{3}$}

Received: 22 March 2018 /Revised: 24 April 2019 / Accepted: 25 April 2019 /

Published online: 23 May 2019

(C) The Author(s) 2019

\begin{abstract}
Stroke is a serious condition and the stroke chain of care is a complex. The present study aims to explore the impact of a computerised decision support system (CDSS) for the prehospital stroke process, with focus on work processes and performance. The study used an exploratory approach with a randomised controlled crossover design in a realistic contextualised simulation experiment. The study compared clinical performance among 11 emergency medical services (EMS) teams of 22 EMS clinicians using (1) a computerised decision support system (CDSS) and (2) their usual paper-based process support. Data collection consisted of video recordings, postquestionnaires and post-interviews, and data were analysed using a combination of qualitative and quantitative approaches. In this experiment, using a CDSS improved patient assessment, decision making and compliance to process recommendations. Minimal impact of the CDSS was found on EMS clinicians' self-efficacy, suggesting that even though the system was found to be cumbersome to use it did not have any negative effects on selfefficacy. Negative effects of the CDSS include increased on-scene time and a cognitive burden of using the system, affecting patient interaction and collaboration with team members. The CDSS's overall process advantage to the prehospital stroke process is assumed to lead to a prehospital care that is both safer and of higher quality. The key to user acceptance of a system such as this CDSS is the relative advantages of improved documentation process and the resulting patient journal. This could improve the overall prehospital stroke process.
\end{abstract}

Keywords Stroke $\cdot$ Decision support $\cdot$ EMS team $\cdot$ Prehospital process

Magnus Andersson Hagiwara

magnus.hagiwara@hb.se

Extended author information available on the last page of the article 


$\begin{array}{ll}\text { Abbreviations } \\ \text { CDSS } & \text { Computerised decision support system service } \\ \text { ER } & \text { Emergency room } \\ \text { ECG } & \text { Electrocardiography } \\ \text { EMS } & \text { Emergency medical service } \\ \text { GRS } & \text { Global rating scale } \\ \text { CRDM } & \text { Clinical reasoning and decision making }\end{array}$

\section{Background}

Prehospital emergency care refers to the work provided by care personnel to patients with acute health problems outside of the hospital, most often in response to emergency calls and dispatch to patients' homes, accident scenes or other locations. Emergency medical services (EMS) clinicians are key actors in this work. They diagnose and provide care on scene and, if needed, transport patients to a medical facility [1]. Quality of care, patient outcomes and thus patient safety is heavily depending on EMS clinicians' ability to make fast and accurate decisions based on structured assessments. This can be challenging in the prehospital domain due to uncertain or unexpected circumstances, safety issues and access constraints, in combination with different levels in training, practices and skills among prehospital care personnel. Furthermore, some care processes are highly time critical. One example of a time-critical process is when being dispatched to a patient with stroke symptoms.

Stroke is a common condition which affects 15 million people worldwide each year. 4.5 million of these will die from the stroke and among survivors, $50 \%$ will have disabilities after 6 months [2]. The EMS is an important link in the stroke process: care provided by EMS clinicians is the first point of access to care for the majority $(>70 \%)$ of patients with stroke symptoms [3]. The prehospital stroke process is complex, involving several time-critical steps and actions. Examples include the following: establishing a field diagnose; determine a time for symptom onset; using protocols for treatment decisions; information exchange and communication with emergency room (ER) and/or neurologists; and producing accurate and reliable documentation.

The full stroke process (the time from symptom onset to definitive care) is determined by and dependent on several factors. One of the most crucial factors is delay time, which can be divided into patient delay and system delay. Patient delay refers to the time from a patient's first symptoms to when they make the first contact with the health care system (e.g. when calling an ambulance). System delay is the time from this first contact until the final diagnosis is established and critical treatment initiated [4]. There are indications that a comprehensive prehospital assessment and early identification of patients with time-critical conditions can decrease the total system delay time even though this includes increased prehospital time [5]. Studies have revealed that patients with stroke benefit from early contact with the health care system, e.g. using EMS rather than seeking care from primary care or using their own means for transportation to an ER. Early recognition of stroke symptoms has a positive effect on minimising 
system delay time, e.g. recognised already at the dispatch centre [6, 7], by EMS clinicians [8] and through early notification to the receiving hospital [9]. There are however challenges related to assessments and decision-making in field settings, such as accurately diagnosing a stroke. Two previous studies have shown that about $35 \%$ of stroke diagnoses (later determined at the hospital) are in fact missed by EMS clinicians $[10,11]$.

Today, the support provided to EMS clinicians to manage patients usually consists of a combination of cognitive tools or expert systems such as paperbased protocols or guidelines, and phone consultations with attending ER physicians or (for stroke symptoms) neurologists. As discussed by Andersson Hagiwara et al. [12] and Söderholm [13], there are however problems with these tools and practices, in the sense that they are not always suitable for the task or compatible with the EMS work process. As an example, EMS clinicians have to use several different paper-based protocols, guidelines, triage systems and medical record documentation sheets or systems, when managing a patient. In complex timecritical prehospital processes such as management of patients with stroke symptoms, it is neither effective nor practical to assemble, find and use all these different sources of critical information, potentially in combination with performing continuous documentation, and using communication gadgets and other tools. Hence, the process could benefit from an integrated computerised decision support system (CDSS) enabling access to medical history, computerised process support (e.g. assessments rules and process guidelines), opportunities to send and receive information to/from medical support and the possibility to document directly in a patient's digital prehospital medical record.

Much of the previous work on CDSS has been done within clinical contexts such as hospitals and primary care, and is reported in a number of systematic reviews [14-17]. These reviews indicate that a CDSS improves patient assessment, increases compliance to guidelines, and as a result has a positive effect on quality of care and patient safety. The largest effect on quality of care is when the CDSS can be used in the direct patient contact [18], e.g. by using handheld devices which is reported to have better effect on care processes than stationary technology [19]. Furthermore, the use of a CDSS can standardise clinical decisionmaking and as a consequence give patients more equal assessment and treatment [18]. One challenge is however that clinical/hospital healthcare settings are very different from prehospital settings in terms of what type of work that is done, the environments, safety factors and people working there. Hence, different healthcare environments require different types of CDSS.

The few studies of CDSS in the prehospital care context indicate that using a CDSS can improve the patient assessment process [20] and increase compliance to guidelines [21], but that the systems need to be carefully tailored to the specific user group and their needs-otherwise technology support could have harmful effects [22]. If the CDSS, e.g. is too difficult to use or cumbersome to set up, it might add unnecessary time to treatment, delay care or not be used in a correct or efficient way. As discussed in a systematic review by Bano et al. [23], there is a strong correlation between user involvement and system success. User participation has been identified as one of the most important factors for system success [24], while failing to understand the intended users has 
repeatedly been reported as a reason to failed system development projects [23, 25-27]. Hence, when designing these types of systems, it is crucial to work in multidisciplinary teams (e.g. including both designers, developers and healthcare professionals), and involve users early in the design process using realistic and contextualised approaches to evaluate the system use and its impact on work processes as well as outcomes.

In this study, we present the results of an evaluation of a CDSS prototype for prehospital stroke managements. The prototype is called PrehospIT and was manufactured by the company Ortivus. It enables interoperability between different systems so that prehospital personnel can access as well as enter information to get continuous decision and documentation support throughout the whole prehospital care process via one single system/interface. We have strived to create a realistic, simulated evaluation environment where real users (EMS clinicians) perform their work in very similar ways to what they usually do, using the CDSS prototype throughout an entire ambulance mission, and then share their perspectives on the advantages and challenges of this specific technology.

\subsection{Study Aims}

The aim of this study is to explore the effects and user perceptions of the PrehospIT CDSS on the prehospital process of managing patients with stroke symptoms. The aim pertains to (1) the impact on work process and performance, and 2) user perceptions of benefits and problems when using the system. The aims have been further operationalised as follows:

1. The PrehospIT CDSS's effect on work process and performance, with respect to:

- EMS teams' clinical performance

- EMS teams' compliance to process recommendations

- Prehospital system delay time

- Work distribution within the team

2. Perceptions of using the PrehospIT CDSS with respect to:

- EMS clinicians' self-efficacy

- Advantages and challenges regarding compatibility and design of the PrehospIT CDSS

The PrehospIT CDSS is intended to be used throughout an ambulance mission, from dispatch to finalising the patient record. This use situation spans several physical locations, and includes different activities such as assessments, decisions and communication, and both using/accessing/gathering and sharing/recording/sending information from and to other stakeholders, locations and actors within the overall healthcare system (see Table 1 for an overview of phases and activities). From an evaluative point of view, this introduces several challenges, which makes real-life evaluation impractical and risky. Therefore, we base our evaluation on a realistic, contextualised simulation approach [28]. 
Table 1 Prehospital phases, activities and PrehospIT CDSS functionality

\begin{tabular}{|c|c|c|}
\hline Phase & Activities and locations & $\begin{array}{l}\text { Functionality and support provided by the } \\
\text { PrehospIT CDSS }\end{array}$ \\
\hline
\end{tabular}
Receiving the - Finding the address; the first priority is to call find the address and best route to the patient
- Assess possible risks; information from the dispatch centre is used to assess safety. Is the address known? Is there information of drug abuse or violence or hazardous environment?
- Gathering supplementary information; is there more information from dispatch centre? Calling the patient or relatives
- Make plans; what is the possible scenario? Who in the team is responsible for what? Which equipment should be brought to the patient? Is there a need for more resources? What do guidelines say?

Arriving at the - Assess possible risks by gathering visual scene information

- Scene assessment; gathering and assessment of information such as weather conditions, light conditions and information of social condition

- First impressions; assessment of information such as body position, skin colour, body constitution, breathing and body movement

On scene - First survey; assessment and treatment of assessment Airway, Breathing Circulation, Disability and and Exposure (ABCDE)

treatment - Second survey; focused patient history, focused assessment, vital parameters and triage

- Clinical decision-making; level of urgency, general treatment decisions, level of care.

- Interventions; on scene treatment

Transport decision and departure

En route assessment and treatment

Handover
- Transport decisions; decisions including leaving the patient at home with self-care advice, transport to primary care, transport to nearest hospital or transport to specialist hospital

- Re-evaluation; ABCDE

- Decisions on transport techniques; best techniques for transport to the ambulance?

- Re-evaluation; ABCDE

- En route assessment; continued focused patient history and assessment

- En route treatment; continued treatment

- En route communication; communication with receiving hospital by phone or text message

- Arrival; preparing the patient for hospital handover
- Possibility to access the patient's chart and medical history

- Access treatment guidelines

- Possibility to make notes about first impressions

- Guidance to perform surveys and assessments in a structured manner

- Functionality to support continuous documentation and recording of assessment results

- Decision support based on findings

- Treatment and process protocols, e.g. mNIHSS for stroke

- Re-evaluation and/or re-assessment based on same support as above

- Notification to hospital and/or neurologist with option to send field record/assessment and mNIHSS-score

- En route assessment and treatment based on same support as above based on same support as above

- Notification to hospital and/or neurologist with option to send field record/assessment and mNIHSS-score

- The use of the system forms the base for a digital prehospital record. The record can 
Table 1 (continued)

\begin{tabular}{|c|c|c|}
\hline Phase & Activities and locations & $\begin{array}{l}\text { Functionality and support provided by the } \\
\text { PrehospIT CDSS }\end{array}$ \\
\hline & $\begin{array}{l}\text { - Handover report; structured handover } \\
\text { report } \\
\text { - Documentation; documentation according } \\
\text { to local routines and systems (paper } \\
\text { based/digital) } \\
\text { - Preparation for new mission; cleaning or } \\
\text { replacement of used equipment } \\
\text { - Reflection; critically analysing clinical } \\
\text { events and outcomes. }\end{array}$ & $\begin{array}{l}\text { be use as member notes in the verbal } \\
\text { handover report } \\
\text { - After the handover the EMS team can finish } \\
\text { the digital prehospital record and send it to } \\
\text { the hospital patient record database. }\end{array}$ \\
\hline
\end{tabular}

\section{Methods}

\subsection{Study Context}

A typical ambulance mission can be divided into a number of defined phases [12, 29, 30]. Earlier simulation studies of ICT technology for prehospital care [20, 22, 31 ] have only focused on one specific phase of the prehospital process, such as on-scene assessment and treatment. It is reasonable to assume that every type of new tool or healthcare technology affects different processes in the overall care chain in different and diverse ways [32]. Therefore, it is crucial to investigate not only specific tasks or outcomes in isolation but also consider the system's impact on the overall work process [33]. To be able to study the use and the effects of a CDSS in relation to the whole prehospital care process, it is important that every phase is included in an evaluation. The evaluation in the present study covers all these phases. The phases and how the PrehospIT CDSS supports the activities in each of these are outlined in Table 1.

\subsubsection{The PrehosplT CDSS System}

The technical set-up of the PrehospIT system consisted of products and components from four different providers (Ortivus, Cerner, SAAB and InterSystems). Together, they represented the following: one ambulance IT-solution (MobiMed, by Ortivus); one electronic health record system (Melior, by Cerner); a PrehospIT specific radiology department client (by SAAB); a PrehospIT specific stroke coordinator client (by Ortivus); a PrehospIT specific alarm and event (A\&E) client (by Cerner); and one registry (HealthShare, by InterSystems). As part of the PrehospIT project, all parties had agreed upon standards, protocols and a system set-up to enable flexible interchange of data between their respective standard products and/or PrehospIT specific components. A central component in the overall system solution was the Registry, which kept track of where information regarding a specific patient (ID) was added and/or stored. Requests to the Registry made from any component in the system set-up, allowed direct retrieval of information related to the specified patient ID from any other source in the system. 
This information was formatted as a HL7 CDA document, ${ }^{1}$ with content coded in accordance with a mutual PrehospIT standard utilising NEMSIS, ${ }^{2}$ Snomed $\mathrm{CT}^{3}$ and a proprietary protocol to handle what was not covered by the existing standards. This system set-up made it possible to support the entire acute stroke chain with real-time input from existing electronic patient records (EPRs) or other data sources available, including real-time field input via the ambulance application evaluated in the present study. It also enabled the various clients (A\&E, Radiology and Stroke coordinator) provided by various companies to retrieve information in real time from any source including the ambulance. Prior to the simulations, the set-up was technically tested and verified in a connectathon workshop (Fig. 1).

\subsection{Study Design}

The study follows the realistic evaluation paradigm [34]. This means that equal attention is paid to the context (the prehospital work process), and to the mechanisms (activities, interactions and tools) within the context. According to Pawson and Tilley [34], mechanisms are always embedded in particular contexts and it is hence necessary to understand effects together with the context, on evaluation outcomes. The study compares the clinical performance between EMS teams using a CDSS and EMS teams using usual paper-based process support. The participating EMS teams were randomised to four different conditions: to start with using CDSS and patient scenario one, start with CDSS and patient scenario two, start without CDSS and patient scenario one, and start without CDSS and patient scenario two. The study design was inspired by the framework of Kannampallil et al. [33] for evaluating clinical cognitive activities in complex real-world environments. See Fig. 2 for study design flowchart.

The teams worked through two simulated patient care scenarios based on patients exhibiting stroke symptoms. Patient 1 was an elderly man with confusion and difficulties to stand up (stroke mimic). The team was dispatched to the person's home where he lived with his partner. For patient 2, the team was dispatched to a 40-year-old man found on the floor at his workplace (a real estate agent's office) by a co-worker. The patient exhibited difficulties to speak and asymmetrical neurological findings. Participating teams were working through the whole ambulance mission outlined in Table 1, including dispatch, driving, arrival, on-scene care, patient interaction, interaction with relatives and bystanders, transport, handover at hospital and final patient chart documentation.

\subsection{Participants and Setting}

The participants were all active EMS clinicians from four different ambulance organisations in Sweden. EMS clinicians in Sweden include (1) ambulance nurses with the main medical responsibility in the EMS team, and (2) emergency medical technicians (EMTs) with a shorter education. This formation somewhat resembles the AngloAmerican system, with paramedics and EMTs. Since 2005, all ambulances in Sweden

\footnotetext{
${ }^{1}$ The HL7 version 3 Clinical Document Architecture (CDA®), http://www.h17. org/implement/standards/product_brief.cfm?product_id=7

2 The National Emergency Medical Services Information System, https://nemsis.org/

${ }^{3}$ SNOMED CT The Global language of healthcare, https://www.snomed.org/snomed-ct
} 


\section{PrehosplT - Systemdesign}

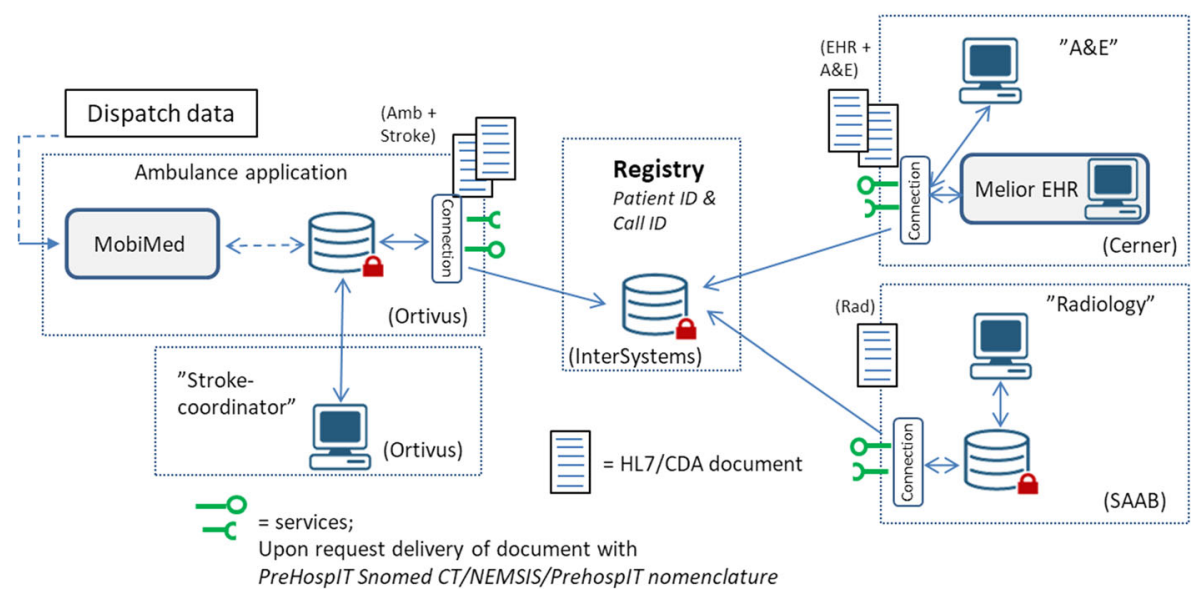

Fig. 1 PrehospIT system design

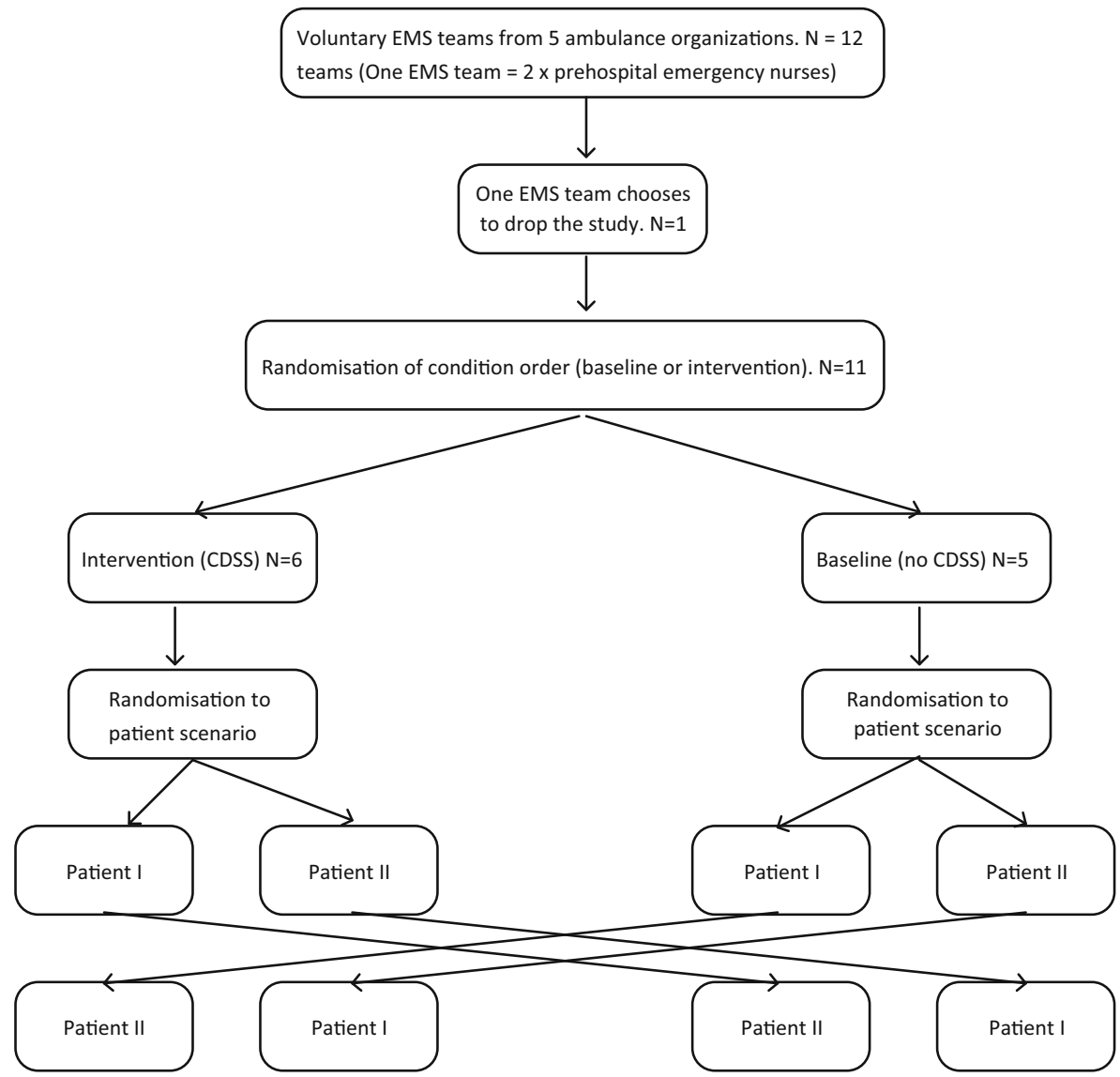

Fig. 2 Experimental design flow-chart 
must be staffed by at least one registered nurse [35] and an EMS team can consist of either two ambulance nurses or one ambulance nurse and one EMT. The teams in our study were recruited through enquiries distributed to managers of EMS organisations asking if any clinicians in their organisation were interested to participate in the study. Twelve teams consisting of 24 EMS clinicians announced an interest to participate. Three weeks before the experiment, they received information via email about the study, the simulation and the CDSS. Eleven teams showed up to participate in the experiment. On arrival at the facility, participants received additional information regarding the study and their participation, and signed an informed consent form. The team was then introduced to the CDSS and was able to interact with and explore the system for approximately $30 \mathrm{~min}$. They also received a 20 -min introduction to the simulation, the patient simulator and the EMS bag and its equipment. The participating clinicians $(15=$ men, $5=$ women, $2=\mathrm{n} / \mathrm{a})$ had a mean age of 41 years $(\mathrm{SD}=8.2)$, averaging 11 years of EMS work experience $(\mathrm{SD}=7.9)$ (Table 2). Based on our experience from the field, this reasonably mirrors the current spread in gender and experience level (no national statistics available).

The experiment was conducted in a simulation facility at an ambulance organisation in south west Sweden. The simulation platform is a part of a research project (SAREK)

Table 2 Participant characteristics

\begin{tabular}{|c|c|c|c|c|}
\hline Team/participant & Sex & & Year of birth & Years in EMS \\
\hline \multirow[t]{2}{*}{ Team 1} & P1 & $\hat{0}$ & 1979 & 6 \\
\hline & $\mathrm{P} 2$ & 우 & 1978 & 13 \\
\hline \multirow[t]{2}{*}{ Team 2} & P3 & $\mathrm{n} / \mathrm{a}$ & $\mathrm{n} / \mathrm{a}$ & $\mathrm{n} / \mathrm{a}$ \\
\hline & P4 & $\hat{0}$ & 1972 & 8 \\
\hline \multirow[t]{2}{*}{ Team 3} & P5 & $\hat{0}$ & 1958 & 27 \\
\hline & P6 & $\mathrm{n} / \mathrm{a}$ & 1971 & 15 \\
\hline \multirow[t]{2}{*}{ Team 4} & P7 & q & 1992 & 4 months \\
\hline & P8 & $\hat{0}$ & 1979 & 7 \\
\hline \multirow[t]{2}{*}{ Team 5} & P9 & $\hat{0}$ & 1989 & 2 \\
\hline & P10 & $\hat{0}$ & 1969 & 14 \\
\hline \multirow[t]{2}{*}{ Team 6} & P11 & q & 1980 & 3.5 \\
\hline & P12 & $\hat{0}$ & 1968 & 25 \\
\hline \multirow[t]{2}{*}{ Team 7} & P13 & $\hat{0}$ & 1974 & 17 \\
\hline & P14 & $\hat{0}$ & 1967 & 19 \\
\hline \multirow[t]{2}{*}{ Team 8} & P15 & $\widehat{0}$ & 1970 & 15 \\
\hline & P16 & $\hat{0}$ & 1965 & 24 \\
\hline \multirow[t]{2}{*}{ Team 9} & P17 & 0 & 1983 & 8.5 \\
\hline & P18 & 우 & 1977 & 13 \\
\hline \multirow[t]{2}{*}{ Team 10} & P19 & $\hat{0}$ & 1987 & 8 months \\
\hline & $\mathrm{P} 20$ & q & 1972 & 1 \\
\hline \multirow[t]{2}{*}{ Team 11} & P21 & $\hat{0}$ & 1974 & 8 \\
\hline & P22 & $\hat{0}$ & 1975 & 12 \\
\hline
\end{tabular}


[36] with the aim to contextualise the prehospital work process using a serious gameinspired approach to accomplish better simulation [37]. The platform has been tested for immersion [38] and has been found superior to traditional simulation where some phases in an ambulance mission are excluded and with lower equipment and environmental fidelity. Using a contextualised simulation, platform was found to affect immersion positively and thus contributes to an improved simulation experience [28].

\subsection{Data Collection and Analysis}

\subsubsection{Performance}

All scenarios were video recorded in their entirety, from dispatch to hand-over. These recordings were used as a basis for measuring teams' performance during scenarios.

The performance measure was based on two parts: time and clinical performance. Time included timestamps of the video recordings that was used to calculate, e.g. on scene time, transport decision and hand-over. Clinical performance was analysed from the video recordings by a panel of six experienced ambulance nurses. To do this a validated instrument, global rating scale for the assessment of paramedic clinical competence (GRS) [39] was used together with a protocol covering the regional prehospital guidelines for stroke assessment and treatment procedures. The GRS instrument was used to evaluate seven competence items plus overall clinical performance (see Table 3). The performance for each item was graded on a 7-point Likert scale ranging from unsafe (1) to exceptional performance (7). In addition to this, the raters used the regional guideline to count performed interventions (performed or not), record whom in the team performing the interventions (1st or 2nd EMS clinician) and to record times for different interventions and phases. Examples of recommended interventions according to the regional prehospital guidelines are first survey and second survey based on the assessment process described in the advanced medical life support (AMLS) course [40] including assessment and treatment of vital functions (airway, breathing, circulation, disability, exposure); structured patient history ${ }^{4}$; and stroke-specific focused assessment. The most important step in the prehospital stroke assessment is the graded neurological examination with the instrument modified National Institutes of Health Stroke Scale (mNIHSS) [41]. It is based on the hospital instrument NIHSS [42] where the neurologist has to decide if the patient can be transported to the nearest hospital with access to computer tomography (CT), bypassing the ER, and treatment with thrombolysis or direct transport to specialist centre with thrombectomy resources. The scale includes 11 items representing different assessments, scored from 0 to 2, 0 to 3 or 0 to 4 . The mNIHSS instrument starts with assessment of level of consciousness, followed by assessment of gaze, visual fields, motor functions of left and right arm, motor functions of left and right leg, and assessment of sensory, language and neglect. The mNIHSS instruments used in the participating ambulance organisations are to some extent different from the original instrument (neglect is excluded and thus has a different max score). Maximum score in the original instrument is 31 , with scores between 2 and 5 indicating minor stroke and scores $>6$ indicating a major stroke involving

\footnotetext{
${ }^{4}$ Structured patient history: signs and symptoms, onset, provocation or palliation, quality of the pain, region and radiation, severity, time, allergies, medications, past illnesses, last oral intake, events leading up to present illness
} 
Table 3 Theoretical constructs used in data analysis (based on technology acceptance and innovation adoption)

\begin{tabular}{ll}
\hline Construct & Definition \\
\hline Relative advantage & Benefits for stakeholders such as patients, physicians or EMS clinicians. \\
& Potential impact on different parts of the care process. Usefulness of \\
the PrehospIT CDSS. & How well the PrehospIT CDSS works in relation to current work practices. \\
Disadvantages for stakeholders/study participant. Situations or contexts \\
where the PrehospIT CDSS would not work or be useful. \\
If the PrehospIT CDSS is perceived as cumbersome or complicated to use or \\
to learn how to use. Dimensions related to interacting with the system and \\
its interface and physical design.
\end{tabular}

major brain vessels. In addition to the mNIHSS instrument, the focused assessment described in the regional guidelines includes electrocardiography (ECG) transmissions to hospital and measurement of serum glucose.

The six raters $(2=$ female, $4=$ male $)$ were all experienced and active ambulance nurses, with a mean experience of 10.2 years $(\mathrm{SD}=4.2)$ and a mean age of 40.0 years $(\mathrm{SD}=7.6)$. Two of the raters had previous experience of using the GRS instrument for rating clinical performance. The analysis session started with instrument training, where the raters together watched one experiment scenario and discussed the rating using the GRS instrument and the additional guideline protocol. After the training session, the raters were independently rating one common scenario. From these results, an inter-rater reliability (IRR) analysis was performed. The IRR was assessed using a two-way mixed, consistency, average-measures intra-class correlation (ICC) [43]. An ICC value over 0.60 is considered a good IRR. The resulting ICC among the six raters was in the excellent range, $\mathrm{ICC}=0.83$, indicating a high degree of agreement. After the IRR analysis, the video recordings were randomised between the six raters so each rater was rating 3 to 4 videos independently ( 22 in total). The raters had not been involved in the design of this particular study, and also rated a number of other scenarios from another experiment involving simulations and devices (including IT). Thus, they were not aware of the differences in any of the experimental conditions they rated, and it was not possible for them to determine if a team was using the CDSS or not. The CDSS was built into the ordinary monitoring equipment used in all of the simulated scenarios and the raters were not able to see the specific actions the EMS teams did on the computer screen.

For sample size calculation, the research group used data from a recent simulation experiment [28] and scored the video recordings from the experiment with the GRS instrument. The sample size calculation was based on results from overall clinical performance. The mean difference between the two conditions in that experiment was 0.83 and the standard deviation 0.83 . With an $\alpha$-level of 0.05 and power of $80 \%$, the calculation gave a minimum of 10 subjects to be able to reject the $\mathrm{H}_{0}$.

To compare differences in time and clinical performance between groups, paired $T$ test was used for data on interval level and for nominal data we used the McNemar test. A $p$ value of $<0.05$ was considered significant in all statistical tests. For all other data, descriptive statistics were used. All statistical analyses were performed using the statistical software program SPSS 21.0 (SPSS Inc., Chicago, IL). 


\subsubsection{Self-Efficacy}

The social cognitive theory of self-efficacy refers to a person's judgement of their capability to perform a certain task [44]. Self-efficacy contributes to future task performance in the sense of skill development and skill retention as it stimulates certain behaviours. High levels of self-efficacy lead to more efforts to solve a challenging problem, and thus additional skills, while low levels of self-efficacy reduce and/or slow down skill development. If the tools used to solve a problem (e.g. technology) are badly designed, disruptive, or lack work-fit, this might harm users' self-efficacy and thus their future performance [45]. For this study, we used a self-efficacy instrument (a post-questionnaire) designed to examine different types of skills (e.g. decision-making, assessment, awareness) in a prehospital mission. EMS clinicians indicated how confident they were that they could perform each task on a 5-point Likert scale $(1=$ strongly disagree; $5=$ strongly agree). Since no self-efficacy questionnaire for the prehospital care work process was available, we developed questions based on Bandura's [46] recommendations and in consultation with prehospital care researchers, instructors and practitioners. A Wilcoxon signed-rank test was used to determine differences between participants working with and without CDSS.

\subsubsection{User Perceptions of the PrehospIT CDSS}

Post-interviews were conducted after the team had worked through the two scenarios. A semi-structured interview guide was used, based on concepts pertaining to technology acceptance [47] and innovation adoption [48]. Questions included teams' perceptions of whether the CDSS was easy to use, easy to learn, how compatible it was with their current way of working, what advantages using the system provided compared with their current practice, and what problems and challenges they experienced when using the system.

Post-interviews were analysed in two steps, first bottom-up to identify initial broad themes (e.g. "positive impact", "negative use experience", "documentation", "current practice"). These were then analysed top-down according to the theoretical constructs (Table 3) and where applicable also organised in an affinity diagram. The affinity diagram is a tool used in, e.g. human-computer interaction and contextual design [49] to visualise themes and their relationships in relation to the work and tasks that a system or design intends to support.

\section{Results}

\subsection{The CDSS Effect on EMS Teams Clinical Performance}

\subsubsection{GRS Scoring of Overall Clinical Performance}

The GRS scoring among the six raters showed statistically significant differences for two items. There was improvement in score of the item "patient assessment" when the team was using the CDSS $(t=-2951, p=0,014)$ mean 
score increasing from $4.09 \pm 0.94$ to $5.27 \pm 0.79$. There was also a significant difference in the item "decision-making" $(t=-3131, p=0,011)$ with increase in GRS score from $4.73 \pm 0.65$ to $5.36 \pm 0.50$ when using the CDSS. There were no significant differences in the other GRS items between when teams were using CDSS or not (Table 4), all of them however exhibiting positive change tendencies except for "resource utilisation" and "procedural skills".

Table 4 Results from GRS rating of teams working as usual compared with working with the PrehospIT CDSS

\begin{tabular}{|c|c|c|c|c|c|c|}
\hline Variable & $\begin{array}{l}\text { Mean } \\
\text { difference }\end{array}$ & SD & $t$ & $\begin{array}{l}95 \% \\
\text { confidence } \\
\text { interval }\end{array}$ & $p$ & $\begin{array}{l}\text { Effect size } \\
\text { (Cohen's } \\
\text { d) }\end{array}$ \\
\hline $\begin{array}{l}\text { Situation awareness } \\
\text { Teams' ability to consider } \\
\text { and integrate environmental, } \\
\text { scene, resources and patient } \\
\text { condition into the overall } \\
\text { management plan. }\end{array}$ & +0.18 & 1.08 & 0.56 & $-0.91-0.54$ & 0.59 & 0.28 \\
\hline $\begin{array}{l}\text { History gathering } \\
\text { Teams' ability to effectively gather } \\
\text { a patient history according to the } \\
\text { clinical situation and level of urgency. }\end{array}$ & +0.25 & 1.06 & 0.82 & $-0.92-0.42$ & 0.43 & 0.40 \\
\hline $\begin{array}{l}\text { Patient assessment } \\
\text { Teams' ability to select and perform } \\
\text { a physical exam and investigation } \\
\text { of signs and symptoms. }\end{array}$ & +1.18 & 1.33 & 2.95 & -2.07 to -0.29 & $0.01 *$ & 1.37 \\
\hline $\begin{array}{l}\text { Decision making } \\
\text { Teams' ability to select } \\
\text { an appropriate and safe } \\
\text { management plan. }\end{array}$ & +0.63 & 0.67 & 3.13 & -1.09 to -0.18 & $0.01 *$ & 0.97 \\
\hline $\begin{array}{l}\text { Resource utilisation } \\
\text { Teams' ability to identify } \\
\text { and use resources effectively } \\
\text { to accomplish goals and } \\
\text { maximise care. }\end{array}$ & -0.18 & 1.33 & 0.45 & $-0.71-1.07$ & 0.66 & 0.18 \\
\hline $\begin{array}{l}\text { Communication } \\
\text { Teams' ability to clearly } \\
\text { exchange information } \\
\text { within the team, patient } \\
\text { and bystanders for optimal } \\
\text { patient care and team effectiveness. }\end{array}$ & +0.54 & 0.93 & 1.96 & $-1.17-0.08$ & 0.08 & 0.90 \\
\hline $\begin{array}{l}\text { Procedural skill } \\
\text { Teams' ability to complete } \\
\text { procedural skills effectively } \\
\text { and in accordance with standards. }\end{array}$ & 0.00 & 1.67 & 0.00 & $-1.12-1.12$ & 1.00 & 0.0 \\
\hline $\begin{array}{l}\text { Overall clinical performance } \\
\text { Overall judgement based on the seven } \\
\text { items. }\end{array}$ & +0.55 & 1.04 & 1.8 & $-1.2-0.15$ & 0.11 & 0.67 \\
\hline
\end{tabular}

*Significant difference; + , higher score with use of CDSS, SD, standard deviation 


\subsubsection{The CDSS Effect on EMS Teams' Compliance to Process Recommendations}

The scoring of the number of accomplished assessments and treatments interventions as described in the prehospital guidelines showed that the CDSS had a positive impact. The teams accomplished significantly more interventions in the first survey (mean differences $+1.82, t=4.8, p=0.01$ ) including assessment and treatments of airway, breathing, circulation, disability and head-to-toe assessment when using the CDSS. There was also a significant difference in stroke-specific assessment as described in the prehospital guidelines where teams accomplished more assessments (mean difference $+2.27, t=3.6, p=<0.001$ ) when using the CDSS. For the total number of assessment and treatment interventions, using the CDSS led to significantly more interventions being performed compared with working as usual without the support of a CDSS (mean difference $+6.0, t=5.10, p=<0.001$ ) (Table 5).

\subsubsection{The CDSS Effect on Prehospital System Delay Time}

The team using the CDSS was spending approximately 4 min longer time compared with the team working as usual without a CDSS. The use of the CDSS also increased the time of notification to neurologist (Table 6). The higher number of performed interventions in the CDSS group can partly explain the reason for this system delay. Number of interventions/min was 0.83 in the CDSS group compared with $0.74 / \mathrm{min}$ in the control group (mean difference $=+0.09 / \mathrm{min}, t=2.52 p=0.03$ ).

\subsubsection{The CDSS Effect on Work Distribution}

Using the CDSS had a tendency to change the EMS teams' work distribution. When teams were using the CDSS, the 2nd EMS clinician performed more assessments and

Table 5 Results of performed enquiries and interventions comparing EMS teams working as usual with when working with CDSS

\begin{tabular}{|c|c|c|c|c|c|c|}
\hline Variable & $\begin{array}{l}\text { Mean } \\
\text { difference }\end{array}$ & SD & $t$ & $\begin{array}{l}95 \% \\
\text { confidence } \\
\text { interval }\end{array}$ & $p$ & $\begin{array}{l}\text { Effect size } \\
\text { (Cohen's } d \text { ) }\end{array}$ \\
\hline $\begin{array}{l}\text { First survey } \\
\quad(\text { rec interventions } n=5)\end{array}$ & +1.82 & 1.25 & 4.8 & -2.66 to -0.98 & $0.01 *$ & 1.71 \\
\hline $\begin{array}{l}\text { History gathering } \\
\quad(\text { rec questions } n=14)\end{array}$ & +1.45 & 2.91 & 1.66 & $-3.41-0.50$ & 0.13 & 0.72 \\
\hline $\begin{array}{l}\text { Focused assessment } \\
\quad(\text { rec enquiries } n=12)\end{array}$ & +2.27 & 1.95 & 3.6 & -3.59 to -0.96 & $<0.01 *$ & 1.60 \\
\hline $\begin{array}{l}\text { Vital parameters } \\
\quad(\text { rec parameters } n=6)\end{array}$ & +0.45 & 0.82 & 1.84 & $-1.01-0.10$ & 0.10 & 0.72 \\
\hline $\begin{array}{l}\text { Interventions } \\
\quad(\text { rec interventions } n=5)\end{array}$ & +0.45 & 1.43 & 1.05 & $-1.42-0.51$ & 0.32 & 0.46 \\
\hline $\begin{array}{l}\text { Total interventions } \\
\quad(\text { rec interventions } n=42)\end{array}$ & +6.00 & 3.90 & 5.10 & -8.62 to -3.38 & $<0.01 *$ & 1.74 \\
\hline
\end{tabular}

*Significant difference; +, higher score when using the CDSS; SD, standard deviation 
Table 6 Critical times for teams using CDSS in compare with teams without

\begin{tabular}{lllllll}
\hline Variable & $\begin{array}{l}\text { Mean } \\
\text { difference } \\
\text { (mm:ss) }\end{array}$ & SD & $t$ & $\begin{array}{l}95 \% \\
\text { confidence } \\
\text { interval }\end{array}$ & $\begin{array}{l}\text { Effect size } \\
\text { (Cohen's } \\
d \text { ) }\end{array}$ \\
\hline $\begin{array}{l}\text { Total scenario time } \\
\begin{array}{l}\text { Total time with patient } \\
\quad \text { on scene and in ambulance) }\end{array}\end{array}$ & $+04: 32$ & $0: 20$ & 2.38 & $-08: 48-00: 17$ & $0.04^{*}$ & 0.78 \\
$\begin{array}{l}\text { On scene time } \\
\begin{array}{l}\text { Time with patient in } \\
\text { ambulance before departure }\end{array}\end{array}$ & $+03: 49$ & $06: 29$ & 1.95 & $-08: 11-00: 32$ & 0.08 & 0.68 \\
$\begin{array}{l}\text { Time to notification to } \\
\text { neurologist }\end{array}$ & $+02: 51$ & $05: 07$ & 1.85 & $-06: 16-06.44$ & 0.09 & 0.64 \\
\hline
\end{tabular}

*Significant difference; +, increased time with use of CDSS, SD, standard deviation

treatment interventions compared with when they worked without the CDSS. The results were not statistically significant but showed a consistent tendency towards that using a CDSS might change how work is distributed within a team (Table 7).

\subsection{Self-Efficacy}

When rating their capability to perform different tasks in a prehospital mission on a 5point Likert scale, EMS clinicians rated their ability high. Overall mean including all 30 self-efficacy items was 4.21 in the CDSS condition and 4.24 in the condition when

Table 7 Number of interventions performed by 1st clinician and 2nd clinician with and without CDSS

\begin{tabular}{llll}
\hline Variable & $\begin{array}{l}\text { Performed by 1st } \\
\text { clinician (valid \%) }\end{array}$ & $\begin{array}{l}\text { Performed by 2nd } \\
\text { clinician (valid \%) }\end{array}$ & $p$ value \\
\hline
\end{tabular}

1st Survey

$\begin{array}{lrrr}\text { Baseline } & 25(80.6) & 6(10.9) & 0.75 \\ \text { CDSS } & 32(74.4) & 11(25.6) & \end{array}$

Anamnesis

$\begin{array}{llll}\text { Baseline } & 32(68.1) & 15(31.9) & 0.80 \\ \text { CDSS } & 29(65.9) & 15(34.1) & \end{array}$

Vital parameters

$\begin{array}{lll}\text { Baseline } & 28(62.2) & 17(37.8) \\ \text { CDSS } & 21(42.9) & 28(57.1)\end{array}$

Stroke specific assessment

$\begin{array}{lll}\text { Baseline } & 43(76.8) & 13(23.2) \\ \text { CDSS } & 46(75.4) & 15(24.6)\end{array}$

Total

$\begin{array}{lll}\text { Baseline } & 128(71.5) & 51(28.5) \\ \text { CDSS } & 126(64.6) & 69(35.4)\end{array}$


clinicians worked without a CDSS. Only small differences were present between the two conditions. A Wilcoxon signed-ranks test detected mixed statistical significant results (at $p<.005$ ). Table 8 is showing an excerpt of the 7 of the 30 items in the full self-efficacy questionnaire exhibiting the largest positive and negative differences (range +0.20 to -0.32 ) between the CDSS condition and the condition with no CDSS.

\subsection{User Perceptions of Using the CDSS During an Ambulance Mission}

\subsubsection{Relative Advantage}

The main advantages of using the CDSS in relation to current practices were related to the following: access to information, process support and documentation and information sharing.

Getting access to information about the patient already during dispatch (Fig. 3) was found beneficial in terms of being able to prepare and plan and to get more background information.

"Already during dispatch I checked the records of past illnesses, because we had the personal information and everything. So already at that stage you get a good insight of what the patient may have suffered or what is important to know, if there are any previous diseases or not." (Team 9)

Some participants however worried that this would narrow their focus and impede them from seeing all possible options: "... the danger in that is so that you don't arrive with a clear preconception about the patient.” (Team 3).

The process support functionality was appreciated by participants. It helped them to remember to perform all assessments according to their guidelines, and that the results of these assessments were recorded simultaneously via the system.

Table 8 Excerpt of results from self-efficacy survey

\begin{tabular}{|c|c|c|c|c|}
\hline I am confident that I can... & $\begin{array}{l}\text { Without } \\
\text { CDSS }\end{array}$ & $\begin{array}{l}\text { With } \\
\text { CDSS }\end{array}$ & $\begin{array}{l}\text { Mean } \\
\text { diff }\end{array}$ & $p$ \\
\hline Perform focused surveys? & 4.00 & 4.20 & +0.20 & .157 \\
\hline Determine a preliminary diagnosis? & 4.00 & 4.20 & +0.20 & .102 \\
\hline $\begin{array}{l}\text { Continuously monitor and provide treatment } \\
\text { and care to the patient during transport? }\end{array}$ & 4.32 & 4.19 & -0.13 & .046 \\
\hline Inform and communicate with the patient? & 4.20 & 4.00 & -0.20 & .206 \\
\hline $\begin{array}{l}\text { Give notice to receiving hospital in } \\
\text { a concise and structured manner? }\end{array}$ & 4.27 & 4.05 & -0.23 & .096 \\
\hline $\begin{array}{l}\text { Communicate and collaborate with } \\
\text { the others in the ambulance team? }\end{array}$ & 4.64 & 4.36 & -0.27 & .058 \\
\hline Distribute roles? & 4.36 & 4.05 & -0.32 & .052 \\
\hline Overall self-efficacy (based on all 30 items) & 4.24 & 4.21 & -0.03 & \\
\hline
\end{tabular}




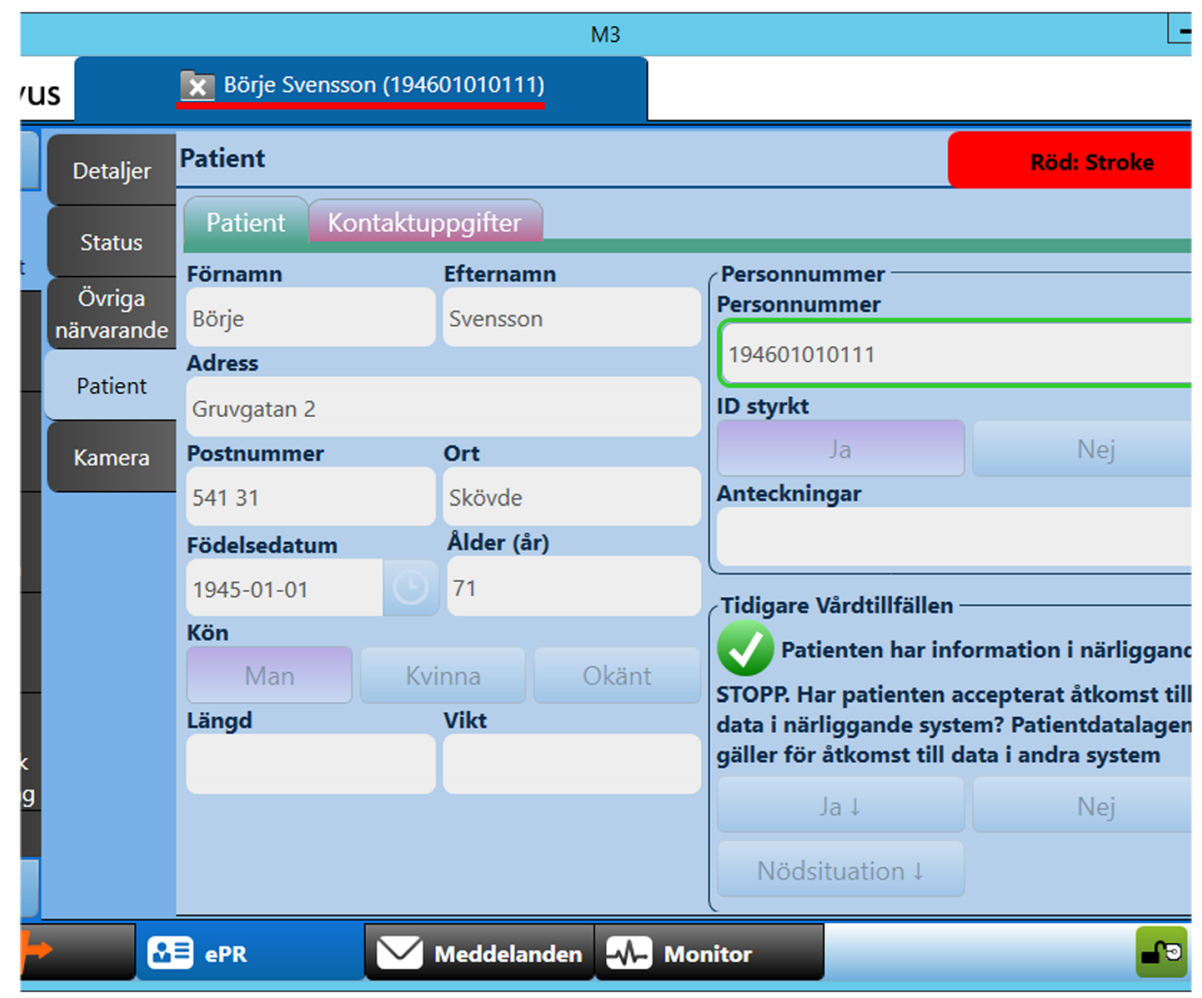

Fig. 3 Screenshot of CDSS providing information during dispatch

“...if you get a little insecure, 'have I forgotten something?' or gets stressed, then I can see if I've checked it and can I go back and do it so that I include all [items], in order to make a good assessment." (Team 8)

"...you do not miss anything, but you'll follow the manual in a better way. I think it can be a great support." (Team 7)

"The [paper] checklist we have in the cars, that you have to flip through to find, [that flipping] disappears since this is digital, I think that was smooth." (Team 11)

Some participants found the process support to be more valuable for cases more in the grey zone than more extreme cases, such as the simulated stroke scenarios:

“... it's far from all [patient cases] that are so clear. (...) here [in this scenario] there were sky high points and one hour from onset... often, I think it's a little more grey zone. Here you might do very well without any support at all-you have to go towards a stroke." (Team 11)

"Abdominal pain, the simple ones where you're not really sure. Not these extreme things. If you have a patient, say priority two [triage], that isn't super urgent in any way, then you have the time to use the system the way I think it's supposed to be [used]." (Team 7) 
One participant explains that some of the process support e.g. for differential diagnosis is more helpful than support to work through basic initial assessment such as ABCD:

"We are thinking $A B C D$ in all situations (...) that is in our role, as obvious as it is when you turn the steering wheel while driving a car. On the other hand, I think that the differential [diagnosis] part is quite interesting (...) it was quite cool anyway, that the more [boxes] you checked the more it [the computer] tried to figure out what this could be about, as a reminder to us that this might perhaps not be a stroke, it may be "this". I think that is good, because if you have not had that thought yourself, the computer will help you to think that thought." (Team 11)

There was however participants who were hesitant, or thought their colleagues would be hesitant, to some aspects of the process support:

“...that a computer would tell us what kind of patient we have, I think some may be sceptical to that. We do better than a computer, I think. Because there is always a scepticism about everything that is new. But to get a patient's journal that writes itself, that would have been rejoiced." (Team 11)

Hence, the strongest advantage using the PrehospIT system was related to documentation, in particular in relation to the patient record.

"It feels like this is really the future. Especially if it [the CDSS] is made so that
what is written becomes the patient's journal, so that we don't have to, like we do
now, write one [ambulance journal] that is to be transferred and then you have to
re-do one [write a new one at the hospital] (-) Then you can actually spend
more time [on one journal], now a lot is missed when you have to write two, that
is our big problem." (Team 8)
"[Using the CDSS] is not double documentation in the same way as when you're
sitting with a paper first... it's getting more in real time as you document." (Team 7)

These statements are not surprising: current documentation practices suffer from a number of problems. The affinity diagram (Fig. 4) illustrates different variations and challenges in the current documentation process that emerged in our data.

As Fig. 3 shows, the main part of the final documentation for the patient chart is often, after being started on scene or during transport, done after handover. Depending on type of EMS system, the final ambulance chart is entered into a digital system either at the hospital or the ambulance station based on unstructured notes or paper journal charts. The ongoing documentation provided by the PrehospIT CDSS would introduce immense benefits with respect to accuracy and patient safety but also lessen workrelated stress. Participants report that the PrehospIT CDSS would provide a number of documentation and information sharing benefits:

“... [benefits for] patient safety and work environment, because it is a stress to go around with those records in your pocket. It feels really bad; you feel that you have not done your job" (Team 2) 


\section{Documentation start}

No documentation

"If we have a critically ill patient then it [documentation] has to wait"

"The patient's journal must never take time from bringing the patient to hospital...
On scene or during transport

"You do not write down triage data until you have loaded and started driving, meanwhile [on scene] you may lose information."

"We take the vital parameters, then write on paper and then type it on a computer"

\section{After hand-over, at hospital or ambulance station}

"There is also a risk when you write the journal if you have had another alarm inbetween, then it will in some way be a later reconstruction of that journal, to which you do not have a direct contact."

"We can't write the journals seven hours later, it does not work if we are to make an adequate assessment."

"This copy, the note, it may be lying in your pocket [...] and then there comes another alarm"

Fig. 4 Illustration of participants' accounts of the current documentation process

"... you can send it [the chart] right away, then [the doctor] can read 20 minutes before we get in [...] and they will receive continuous updates" (Team 4)

"The most valuable is that the times are recorded... exactly everything. Because today, our times do not make sense when you come in with a stroke patient. 'Well how long ago was that?' You do not even know what time you arrive at the patient, so you look at the dispatch time, and then you try to plot a little bit, 'that might have taken a quarter." (Team 1)

In order to (1) get this type of accurate and reliable documentation output and (2) to get the process support such as differential diagnoses suggestions or stroke-specific guidelines/support, continuous input of information into the CDSS while assessing and treating the patient is required. Doing so, raised issues related to the CDSS' compatibility with current ways of working.

\subsubsection{Compatibility}

Although the CDSS was found to be compatible content-wise with the prehospital process - in terms of containing relevant and useful information and providing relevant types of support, it was not fully compatible with the work process, especially when it came to using it to input information during patient care: 
"...but you also have to do that while you see the patient. (-) When you start that care chain, get the score, send the alarm. If you compare that with our paper, there are five points and what we do on these trigger the alarm. Here these points were to be filled in, I thought that was very difficult, especially with the computer."

All participants raised concerns about difficulties to focus on the patient while using the CDSS. This was their most prominent concern with the CDSS.

"I felt that now I have to set my brain to computer mode, then I have to switch back to patient mode again" (Team 5)

Furthermore, using the system was not compatible with the current roles and distribution of work within the team. Many teams expressed confusion about their roles and work division when using the CDSS even though some tried to prepare for this during dispatch:

"It was a little trouble in how to use the computer support. We had some discussion on the way out: [if] one person talks to the patient and the other will check and supplement with something, how to make that work as smoothly as possible. Or would it be the one who does it [talks to the patient] also should work the computer? That felt a little bit, we felt we do not really know how to do it. (-) Though it's something you have to try out." (Team 8)

"We had decided that you would mark [things done on the computer] but once we got to the patient so... when I looked at you... 'but this will not work, maybe I'll take the computer instead." (Team 3)

This also included difficulties to coordinate their work, sometimes due to lack of awareness where in a process or protocol the other person "were":

"When standing next to him, and he uses the computer, the cooperation gets harder as well. Otherwise, we are with the patient and talking. Now he has to sit and concentrate there [at the computer] and I'll have to wait a bit here and ask "will we do that now?" Then he is elsewhere in his mind according to the computer, where I am not. Collaboration is complicated when [doing this]. So Ifelt that it took longer because of it, because the cooperation did not really flow as quickly." (Team 5)

As several teams suggest, there is a need to rethink how work is divided so that responsibilities for documentation and focusing on the patient is in balance within the team:

"I felt that I was busy with it because I did not get it completely. Otherwise when you work, one cares for the patient, and the other notes the parameters. Now I would sit with it [the computer], I did not get all the information from the patient. So, really, it's the other caregiver who's should sit and type the data? (-) We talked a bit about it earlier, that now maybe [2nd EMS] gets a bigger role to take control since I'm going to check [the boxes in the computer]. Actually, one should have done the opposite, that [2nd EMS] would have recorded what I reported to 
that person, if I was to be $1^{s t}$ EMS anyway. If I am responsible for the care, then I want to have that contact with the patient and then someone else will have to fill in those parameters [in the computer]." (Team 6)

If done correctly, using the CDSS could improve the coordination and mutual awareness within the team:

"But I think the flow will be better if the $1^{\text {st }}$ EMS takes the vital parameters, reports, speaks aloud, then you get a communication where you [2nd EMS] gets a picture [of what's happening]" (Team 3)

Overall, the means to input information using the CDSS does not add any advantages compared with current paper-based practice; the output is however seen as superior to what is produced today in terms of accuracy, information sharing and patient safety.

\subsubsection{Complexity}

All teams thought the PrehospIT CDSS provided relevant support and correct and relevant content. They found it easy to learn and that the introduction they received before the simulation was sufficient. Several commented however, that they needed to use it more in order to feel comfortable with using it, e.g. through simulations.

"... even though you were allowed look at it before [the scenario], the questions did not come up until you really sat down [facing] all the buttons" (Team 9) "I do not think that even if we had added 40 minutes to the introduction, I do not think it would have been better... you have to use it for real a little bit." (Team 11)

Hence, the issues identified above with respect to difficulties to focus on the patient while using the CDSS, and thus the need to re-coordinate the work within the team, are connected to the complexity of the interface design: "The system needs to be easier to use in order to not take away the focus from the patient" (Team 1).

The interface of the Prehospit CDSS was perceived as messy and difficult to navigate in. Negative aspects expressed by several teams included "too much scrolling", "difficult to get an overview", "difficult to navigate and find where content is located", "too many menues and sub menues".

Participants mentioned several ways in which the interface design could be improved:

"An alternative to browsing, for example, if you want to use the checklist would be that as soon as I enter a response to a question item then the next one is automatically showed. Then you keep an eye on the screen and ask [the patient] that question" (Team 1)

Furthermore, several participants mentioned features they missed, although these actually were available in the system. Hence, the interface design lacks visibility, in terms that it sometimes wasn't obvious what was possible to do. As Figs. 3 and 5 show, there are boxes for writing comments in free text but participants still asked for the option to do so, not only use boxes and set alternatives. 


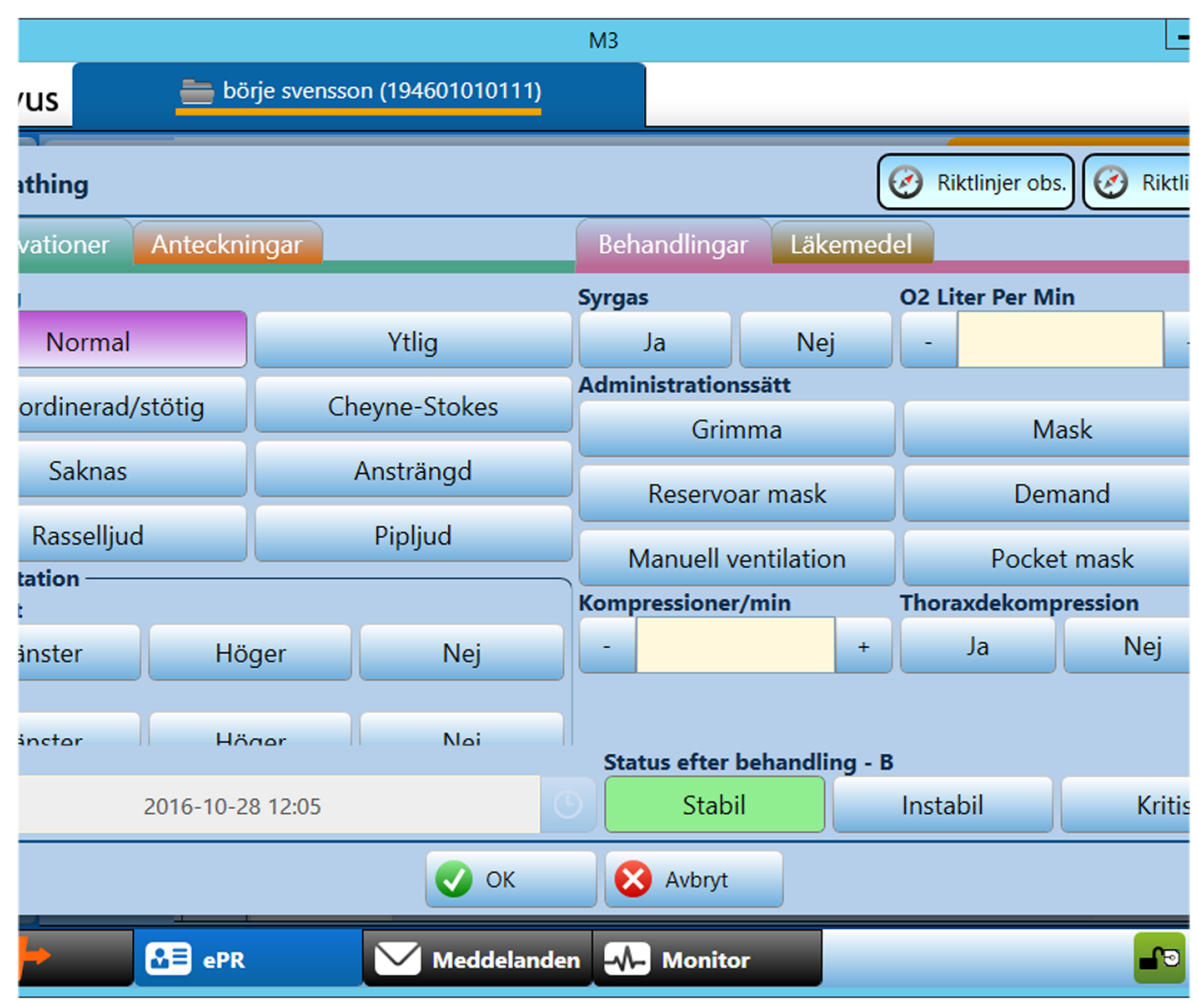

Fig. 5 Screenshot of one of the interfaces for recording information in the CDSS

When considering the reported difficulties to use the system, it is however important to keep in mind that this was the first time participants used it, and that it will take some more time to learn. As participants reflect:

"It's the first [time] and then of course, it feels a little bit messy. Should I do the same thing tomorrow, I might have learned the ropes a bit more." (Team 6)

When it comes to hardware-related aspects such as interacting with the PrehospIT CDSS, this is done through entering text via a keyboard, and through using a pen/ pointer to scroll, push buttons and cross checkboxes etc. Participants were hesitant to this and found it difficult and potentially even more difficult if being under stress or while driving:

"And even worse if you're in the car while driving, then you jump around [when trying to scroll]." (Team 8)

Some suggested that the physical design was too cumbersome and felt outdated and that more current technology should be used, e.g. that support touch-based interaction, similar to an iPad or smartphone. 
“... a menue like a cell phone's [menue] that you can enlarge instead of having a touchpad pointer (-) people are used to cell phones. (-) A smaller tablet but still the same functions (-) Yes, like an iPad, not this large thing." (Team 3)

There were also issues raised regarding hygiene:

"Like this screen with these keys, it cannot be kept clean. You should have something that's pretty flat if it's supposed to work." (Team 6)

Overall, the system was perceived as easy to learn and use. Complexity issues include interface design and physical design that currently should be better adapted to the prehospital care context.

\section{Discussion}

When teams were using the CDSS, significant improvements were found in the two GRS items referring to patient assessment and decision-making. These findings are not surprising. It is during the on-scene assessment and treatment an ambulance team makes most decisions and it is also in this phase of a mission that they have the least support [29]. One earlier study [12] revealed that the physical format of current paperbased guidelines and protocols makes explicit use difficult in the critical on-scene phase. To be able to effectively use guidelines and protocols during direct patient contact is considered as an important feature for safe healthcare [18].

The increased compliance to process recommendations found in the present study is in line with previous research. In a previous simulation study [20] on-scene assessment and treatment of two simulated patient cases, a CDSS did significantly increased EMS teams' compliance to assessment recommendation and anamnesis. That CDSS was partly based on the same platform as the PrehospIT system and had a similar interface. One reason for the increased compliance compared with paper-based guidelines is probably the explicit, step-wise use of guidelines prompted by the CDSS. When using the CDSS, the EMS clinicians take part of the process recommendation in the same process and system interface as working through their patient assessment. The teams using the CDSS spent a longer time on-scene. Previous work [20] reports similar results when a CDSS was used in simulations, although when later evaluated in a clinical study, [21] the effect of increased on-scene time however disappeared. This result suggests that the increased on-scene time induced by the PrehospIT CDSS could be partly explained by the short introduction of the system in connection to the experiment. However, although a longer prehospital time may be negative for patients with stroke, it is important to emphasise that if the extended time is caused by a more accurate assessment, the total time to final care may be shortened.

As previous work [15] discuss, new technology such as a CDSS requires some type of incitement or relative advantage [48] compared with current ways of doing things in order to be accepted and effectively used. The key to acceptance for the PrehospIT CDSS is the continuous real-time documentation of assessments and treatment results generating a complete patient journal accessible for the ER. This has several advantages: (1) Information is recorded in real time, close to the first patient contact rather 
than hours or even days afterwards. It is reasonable to assume that this would lead to more reliable patient data. (2) It addresses the issue discussed by Söderholm et al. [50] that when physicians at the ER or later in the healthcare chain make crucial medical decisions, they seldom have access to the prehospital patient journal or information from scene such as mechanism of injuries, physical findings or any prehospital treatments [51]. The prehospital information is crucial for preparation and for determining further course of treatment; however, a large amount of this is lost during hand over [52] and thus not accessible for the physician [53]. Being able to send a journal draft during transport gives the ER team more information early and thus time to prepare, and makes the process less dependent on a verbal handover report. This is especially important in time-critical processes such as stroke.

Overall, our results suggest a small impact of this CDSS on participants' selfefficacy. This is important because badly designed systems might harm self-efficacy and thus future performance [45]. The largest differences in self-efficacy between conditions are found in items regarding assessment and establishing a preliminary diagnosis (participants' self-efficacy was higher for these items in the CDSS condition) and in items related to patient interaction, team coordination and communication, where participants' self-efficacy was lower in the CDSS condition. These results mirror the GRS rating as well as post-interview results, in terms of that the CDSS provided support in assessment and diagnosis, but interfered with the patient interaction and teams' work distribution process.

While the positive impact and relative advantages of the PrehospIT CDSS are several, the interface design was perceived as cumbersome and quite difficult to use during an ongoing care process. In particular, participants found it difficult to handle the constant move between focusing on the CDSS and the patient. The two modes can be attributed to the reasoning styles/systems described in dual process theory [54]. According to this theory, people use two systems of reasoning: system 1 which is fast, unconscious and automatic, and system 2 which is slow and analytical. The two systems are both in use during clinical reasoning decision-making (CDRM), but in emergency medicine, system 1 is dominating the process [55]. This system is more prone to decision bias, e.g. clinicians making premature decisions and not finishing assessment processes [56]. It is more common in urgent situations where patients show symptoms of failure in vital functions than in more stable situations when there is time for more analytical reasoning (system 2) [57, 58]. In prehospital care, system 2 reasoning is supported by cognitive tools, e.g. guidelines, protocols and algorithms [29]. This has been referred to as system 2-by proxy, and includes elements of algorithmic reasoning and ruling out the worst case scenario [59]. As suggested by our results, the easy, integrated access to guidelines and process support provided by the PrehospIT CDSS prompts the clinician to use a more analytical style of reasoning (system 2). This leads to a more complete and structured assessment of the patient. But, as the participants in the present study express, the constant switching between the patient (e.g. quickly deteriorating patient prompting a fast and more automatic system 1 response) and system/computer mode was a cognitive challenge impacting the process and the team dynamics. This emphasises the importance of a physical and intuitive interface that is truly designed for the intended users and their specific context in order to minimise cognitive load when using the system [60]. Content wise, the interface should provide a clear overview of the work process while not being too crowded; and 
also support easy interaction, e.g. touch-based interaction or voice interaction similar to the interaction technologies used in smartphones and tablets [60].

As several of our results suggest, both the team work process and patient interaction was affected by the CDSS. Changes in team work process was reflected in the negative GRS rating score for the item resource utilisation (Table 4); changes in how work was distributed within the team (Table 7); a negative mean difference in self-efficacy items related to team and patient interaction (Table 8); and participants' accounts of difficulties to focus on the patient and to coordinate the work within the team while simultaneously using the CDSS. It is reasonable to assume that the issues related to cognitive challenges, teamwork and patient interaction to some extent (in addition to the design issues previously mentioned) also was due to that this was the first time participants used the CDSS. Even though everyone thought preparation time was sufficient, in order to be fully comfortable with the system, they need to work with it and apply it continuously to real situations. These results also highlight the importance of agreeing on how to coordinate a team work process and roles, e.g. who should perform exams, interact with the patient and use and operate the CDSS system. The use of contextualised simulation to explore the use of the CDSS was highly appreciated by all teams. Hence, we strongly recommend that when a new tool such as a CDSS is developed and later implemented, training in context, e.g. contextualised immersive simulation proposed by Engström et al. [28] is required. This approach also helped us to explore use and impact of the system for different phases of the process, e.g. early documentation as a mechanism for improved coordination between field and ER and identify areas for improvement regarding the system design.

\section{Limitations}

In this evaluation, we included the entirety of the prehospital work process in the simulated scenarios. One limitation of our approach is, however, that we do not include any inquiries/data from physicians with respect to perceptions of information sent from the scene or ambulance via the CDSS, such as preliminary patient chart and mNIHSS assessment done on scene. To be able to include that in the study, a simulated hospital set-up would have been required, in addition to coupling every team with a corresponding number of consulting neurologists and/or ER physicians. This was not feasible for us to do in terms of time frames, resources and availability of physicians. It is however crucial in future studies to also include the hospital side as well as perspectives from physicians, that is - what do the people at the hospital do with the information sent from the scene?

Another limitation is that the analysis is done on team level only. Both our quantitative and qualitative results point towards changes in work distribution and potentially work roles when using the PrehospIT CDSS. This will be further analysed and reported in a subsequent publication.

In this study, we used paper-based processes as baseline since this currently is the most common practice in Swedish prehospital care. This is a potential limitation since other geographical regions might have other practices and/or use other types of CDSS. 


\section{Conclusions}

Using CDSS might improve patient assessment, decision making and compliance to process recommendations. The key to user acceptance is the advantages of improved documentation and the resulting patient journal. This could improve the overall prehospital stroke process and bridge the information gap between ambulance and hospital. Negative effects of the CDSS include increased on-scene time and a cognitive burden of using the system, affecting patient interaction and collaboration with team members.

Acknowledgements The authors would like to thank the Skaraborg hospital ambulance organisation for all their hard work and support during the experiment. We also thank the research team at the serious games department at University of Skövde, Mikael Lebram, Mikael Johannesson and Per Backlund, for all their help with running the experiment and the simulation platform design. Last but not least, we thank all the participating EMS teams from the ambulance organisations in Gothenburg, South Älvsborg, Skaraborg, North Älvsborg and Norrbotten.

Authors' Contributions Magnus Andersson Hagiwara (MAH) was responsible for designing and conducting the experiment, data collection, analysis and took the lead in writing the paper with HMS. Bengt Arne Sjöqvist (BAS) was responsible for the PrehospIT project, the overall study design and leading the technical development of the integrated PrehospIT CDSS. Lars Lundberg (LALU) assisted in designing and conducting the experiment, acted as a standardised physician for consultation and hand-over during scenarios, provided medical expertise and contributed to the final manuscript of the paper. Hanna Maurin Söderholm (HMS) assisted in designing and conducting the experiment, acted as a standardised relative or co-worker during scenarios, performed data collection (participant observations and post-session interviews) and analysis and took the lead in writing the paper with MAH.

Funding This work was funded by VINNOVA, University of Borås and Västra Götalandsregionen (Regionutvecklingsnämnden, contract RUN 2016-01341).

Data AvailabilityThe main data set consist of video recordings of EMS teams in action. Parts of the data set can be provided on request. Please contact first author.

\section{Compliance with Ethical Standards}

The study was carried out in accordance with the ethical guidelines for research outlined in the Declaration of Helsinki [61]. All participants signed a document of informed consent and were informed about the study both verbally and in text. The study was approved by the Regional Ethics Committee, Gothenburg, Sweden (Dnr: 730-16).

Consent for Publication All authors have read and approved the final manuscript for publication.

Conflict of Interest The authors declare that there are no conflicts of interests.

Open Access This article is distributed under the terms of the Creative Commons Attribution 4.0 International License (http://creativecommons.org/licenses/by/4.0/), which permits unrestricted use, distribution, and reproduction in any medium, provided you give appropriate credit to the original author(s) and the source, provide a link to the Creative Commons license, and indicate if changes were made.

\section{References}

1. The Ems Examination Task Force American Board Of Emergency M, Perina DG, Pons PT, Blackwell TH, Bogucki S, Brice JH, Cunningham CA, Delbridge TR, Gausche-Hill M, Gerard WC et al (2012) The core content of emergency medical services medicine. Prehospital Emergency Care. 16:309-322

2. Warburton E, Alawneh JA, Clatworthy PL, Morris RS (2011) Stroke management. BMJ Clin Evid 0201 
3. Appelros P, Jonsson F, Åsberg S, Asplund K, Glader E-1, Åsberg KH, Norrving B, Stegmayr B, Terént A (2014) Trends in stroke treatment and outcome between 1995 and 2010: observations from riks-stroke, the Swedish stroke register. Cerebrovasc Dis 37:22-29

4. Herlitz J, Thuresson M, Svensson L, Lindqvist J, Lindahl B, Zedigh C, Jarlöv M (2010) Factors of importance for patients' decision time in acute coronary syndrome. Int J Cardiol 141:236-242

5. Hagiwara M, Bremer A, Claesson A, Axelsson C, Norberg G, Herlitz J (2014) The impact of direct admission to a catheterisation lab/CCU in patients with ST-elevation myocardial infarction on the delay to reperfusion and early risk of death: results of a systematic review including meta-analysis. Scandinavian Journal of Trauma, Resuscitation and Emergency Medicine 22:67

6. Fassbender K, Balucani C, Walter S, Levine SR, Haass A, Grotta J (2013) Streamlining of prehospital stroke management: the golden hour. Lancet Neurol 12:585-596

7. Sundström BW, Hagiwara MA, Brink P, Herlitz J, Hansson PO (2017) The early chain of care and risk of death in acute stroke in relation to the priority given at the dispatch centre: a multicentre observational study. Eur J Cardiovasc Nurs 16(7):623-631

8. De Luca A, Toni D, Lauria L, Sacchetti ML, Giorgi Rossi P, Ferri M, Puca E, Prencipe M, Guasticchi G (2009) An emergency clinical pathway for stroke patients-results of a cluster randomised trial (isrctn41456865). BMC Health Serv Res 9:14

9. Bae HJ, Kim DH, Yoo NT, Choi JH, Huh JT, Cha JK, Kim SK, Choi JS, Kim JW (2010) Prehospital notification from the emergency medical service reduces the transfer and intra-hospital processing times for acute stroke patients. J Clin Neurol 6:138-142

10. Wireklint Sundström B, Herlitz J, Hansson PO, Brink P (2015) Comparison of the university hospital and county hospitals in western Sweden to identify potential weak links in the early chain of care for acute stroke: results of an observational study. BMJ Open 5:e008228

11. Brandler ES, Sharma M, McCullough F, Ben-Eli D, Kaufman B, Khandelwal P, Helzner E, Sinert RH, Levine SR (2015) Prehospital stroke identification: factors associated with diagnostic accuracy. J Stroke Cerebrovasc Dis 24:2161-2166

12. Andersson Hagiwara M, Suserud B-O, Jonsson A, Henricson M (2013) Exclusion of context knowledge in the development of prehospital guidelines: results produced by realistic evaluation. Scand J Trauma Resusc Emerg Med 21:46

13. Maurin Söderholm H (2013) Emergency visualized : exploring visual technology for paramedicphysician collaboration in emergency care. Högskolan i Borås, Borås

14. Garg AX, Adhikari NKJ, McDonald H, Rosas-Arellano MP, Devereaux PJ, Beyene J, Sam J, Haynes RB (2005) Effects of computerized clinical decision support systems on practitioner performance and patient outcomes: a systematic review. JAMA. 293:1223-1238

15. Kawamoto K, Houlihan CA, Balas EA, Lobach DF (2005) Improving clinical practice using clinical decision support systems: a systematic review of trials to identify features critical to success. BMJ: $\mathrm{Br}$ Med J 330:765-768

16. Shojania Kaveh G, Jennings A, Mayhew A, Ramsay Craig R, Eccles Martin P, Grimshaw J (2009) The effects of on-screen, point of care computer reminders on processes and outcomes of care. In: Cochrane database of systematic reviews. John Wiley \& Sons, Ltd, Chichester, UK

17. Sintchenko V, Magrabi F, Tipper S (2007) Are we measuring the right end-points? Variables that affect the impact of computerised decision support on patient outcomes: a systematic review. Med Inform Internet Med 32:225-240

18. Morris AH (2002) Decision support and safety of clinical environments. Qual Saf Health Care 11:69-75

19. Prgomet M, Georgiou A, Westbrook JI (2009) The impact of mobile handheld technology on hospital physicians' work practices and patient care: a systematic review. JAIMA 16:792-801

20. Hagiwara MA, Sjöqvist BA, Lundberg L, Suserud B-O, Henricson M, Jonsson A (2013) Decision support system in prehospital care: a randomized controlled simulation study. Am J Emerg Med 31:145-153

21. Andersson Hagiwara M, Suserud B-O, Andersson-Gare B, Sjoqvist B, Henricson M, Jonsson A (2014) The effect of a computerised decision support system (CDSS) on compliance with the prehospital assessment process: results of an interrupted time-series study. BMC Med Inform Decis Mak 14

22. Söderholm HM, Sonnenwald DH, Manning JE, Cairns B, Welch G, Fuchs H (2008) Exploring the potential of video technologies for collaboration in emergency medical care: part II. Task performance. JAIMA 59:2335-2349

23. Bano M, Zowghi D (2015) A systematic review on the relationship between user involvement and system success. Inf Softw Technol 58:148-169

24. Subramanyam R, Weisstein F, Krishnan M (2010) User participation in software development projects. Commun ACM 53:137-141 
25. Lynch T, Gregor S (2004) User participation in decision support systems development: influencing system outcomes. Eur J Inf Syst 13:286-301

26. Kujala S (2008) Effective user involvement in product development by improving the analysis of user needs. Behav Inf Technol 27:457-473

27. Martikainen S, Korpela M, Tiihonen T (2014) User participation in healthcare IT development: a developers viewpoint in Finland. Int J Med Inform 83:189-200

28. Engström H, Andersson Hagiwara M, Backlund P, Lebram M, Lundberg L, Johannesson M, Sterner A, Maurin Söderholm H (2016) The impact of contextualization on immersion in healthcare simulation. Adv Simul 1:1-11

29. Jensen J, Croskerry P, Travers A (2011) EMS: consensus on paramedic clinical decisions during highacuity emergency calls: results of a Canadian Delphi study. CJEM 13:310-318

30. Carter H, Thompson J (2015) Defining the paramedic process. Aust J Prim Health 21:22-26

31. Lammers R, Byrwa M, Fales W (2012) Root causes of errors in a simulated prehospital pediatric emergency. Acad Emerg Med 19:37-47

32. Patel VL, Kaufman DR, Arocha JF (2002) Emerging paradigms of cognition in medical decisionmaking. J Biomed Inform 35:52-75

33. Kannampallil TG, Abraham J, Patel VL (2016) Methodological framework for evaluating clinical processes: a cognitive informatics perspective. J Biomed Inform 64:342-351

34. Pawson R, Tilley N (1997) Realistic evaluation. SAGE, London

35. Suserud B-O (2005) A new profession in the pre-hospital care field - the ambulance nurse. Nurs Crit Care 10:269-271

36. Backlund P, Engström H, Johannesson M, Lebram M, Andersson Hagiwara M, Lundberg L, Maurin Söderholm H (2017) The S.A.R.E.K simulation environment: technical description of a flexible training environment for prehospital care. In: IIT Technical Reports, HS-IIT-TR-17-001. http://urn.kb. se/resolve?urn=urn:nbn:se:his:diva-13558

37. Backlund P, Engström H, Andersson Hagiwara M, Johannesson M, Maurin Söderholm H (2015) Enhancing immersion with contextualized scenarios: role-playing in prehospital care training. In: VSGames. Skövde, Sweden. Accesed 02 Sept 2017

38. Hagiwara MA, Backlund P, Söderholm HM, Lundberg L, Lebram M, Engström H (2016) Measuring participants' immersion in healthcare simulation: the development of an instrument. Adv Simul 2016(1):1-9

39. Tavares W, Boet S, Theriault R, Mallette T, Eva KW (2012) Global rating scale for the assessment of paramedic clinical competence. Prehosp Emerg Care 17(1):57-67

40. Dalton AL (2010) Advanced medical life support: a practical approach to adult medical emergencies. Pearson, Upper Saddle River

41. Meyer BC, Lyden PD (2009) The modified National Institutes of Health Stroke Scale: its time has come. Int J Stroke 4:267-273

42. Lyden P (2017) Using the National Institutes of Health Stroke Scale. A Cautionary Tale 48:513-519

43. Hallgren KA (2012) Computing inter-rater reliability for observational data: an overview and tutorial. Tutor Quant Methods Psychol 8:23-34

44. Bandura A (1997) Self-efficacy: the exercise of control. W. H. Freeman, Basingstoke

45. Söderholm HM, Sonnenwald DH, Manning JE, Cairns B, Welch G, Fuchs H (2008) Exploring the potential of video technologies for collaboration in emergency medical care: part II. Task performance. J Am Soc Inf Sci 59

46. Bandura A (2006) Guide for constructing self-efficiency scales. In: Self-efficacy beliefs of adolescents. Information Age Publishing, Charlotte, NC, pp 307-337

47. Davis FD, Davis GB, Morris MG, Venkatesh V (2008) User acceptance of information technology: toward a unified view. Inf Syst Dev 8:287-335

48. Rogers EM (2003) Diffusion of innovations. Free press, New York

49. Holtzblatt K, Beyer H (2016) Contextual design: design for life. Elsevier Science, San Francisco

50. Söderholm HM, Sonnenwald DH (2010) Visioning future emergency healthcare collaboration: perspectives from large and small medical centers. JAIMA 61:1808-1823

51. Zhang Z, Sarcevic A, Burd RS (2013) Supporting information use and retention of pre-hospital information during trauma resuscitation: a qualitative study of pre-hospital communications and information needs. AMIA Ann Symp Proc 2013:1579-1588

52. Carter AJE, Davis KA, Evans LV, Cone DC (2009) Information loss in emergency medical services handover of trauma patients. Prehosp Emerg Care 13:280-285

53. Bledsoe BE, Wasden C, Johnson L (2013) Electronic prehospital records are often unavailable for emergency department medical decision making. West J Emerg Med 14:482-488 
54. Evans JS (2008) Dual-processing accounts of reasoning, judgment, and social cognition. Annu Rev Psychol 59:255-278

55. Croskerry P (2009) A universal model of diagnostic reasoning. Acad Med 84:1022-1028

56. Croskerry P (2009) Clinical cognition and diagnostic error: applications of a dual process model of reasoning. Adv Health Sci Educ Theory Pract 14 Suppl 1:27-35

57. Wireklint Sundström B (2005) Förberedd på att vara oförberedd : en fenomenologisk studie av vårdande bedömning och dess lärande i ambulanssjukvård. Växjö University Press, Växjö

58. Leblanc VR, Regehr C, Tavares W, Scott AK, Macdonald R, King K (2012) The impact of stress on paramedic performance during simulated critical events. Prehosp Disaster Med 27:369-374

59. Jensen JL (2011) Paramedic clinical decision-making: result of two Canadian studies. J Paramed Pract 1: 63-71

60. Sharp H (2015) Interaction design: beyond human-computer interaction, 4th edn. Wiley, Chichester

61. The World Medical Association (2008) Ethical principles for medical research involving human subjects

Publisher's Note Springer Nature remains neutral with regard to jurisdictional claims in published maps and institutional affiliations.

\section{Affiliations}

\section{Magnus Andersson Hagiwara ${ }^{1} \cdot$ Lars Lundberg $^{1} \cdot$ Bengt Arne Sjöqvist $^{2} \cdot$ Hanna Maurin Söderholm ${ }^{3}$}

Lars Lundberg

lars.lundberg@hb.se

Bengt Arne Sjöqvist

bengt.arne.sjoqvist@chalmers.se

Hanna Maurin Söderholm

hanna.maurin@hb.se

1 PreHospen - Centre for Prehospital Research, Faculty of Caring Science, Work Life and Social Welfare, University of Borås, SE-50190 Borås, Sweden

2 Department of Electrical Engineering, Biomedical Signals and Systems, Chalmers University of Technology, SE-412 96 Gothenburg, Sweden

3 PreHospen-Centre for Prehospital Research, Faculty of Librarianship, Information, Education and IT, University of Borås, SE-50190 Borås, Sweden 